\title{
Pelatihan Membubut Untuk Karang Taruna di Pedukuhan Bromonilan, Purwomartani, Kalasan, Sleman
}

\author{
Iva Mindhayani \\ Program Studi Teknik Industri, Fakultas Teknik, , Universitas Widya Mataram \\ ivamindhayani@gmail.com
}

\begin{abstract}
This community service is a form of a lecturer tri dharma college so that it can provide benefits to the community. In addition, the purpose of this activity is to provide knowledge to youths in the Bromonilan Purwomartani in Kalasan Sleman in terms of: 1) understanding the lathe tool theory, 2) knowing how to operate a lathe, 3) Knowing how to maintain lathe, 4) making simple workpieces. This service activity is to provide basic skills with theory and practice turning to youths, especially those who drop out of school, to have the provision and practical knowledge of turning so that in times of difficulty in finding work they can be self-employed, create their own jobs and support themselves. So that in general it can reduce unemployment, which in turn will be able to reduce the level of poverty. Training is held on Monday-Tuesday, April 16-17 2018 at the Laboratory of Industrial Engineering, Widya Mataram University. The training was attended by youth from Padukuhan Bromonilan and students of industrial engineeringUWM as many as 15 participant. After training for 2 days, it was known that: 1) knowledge about turning lathe, 2) also knowing how to operate the lathe, 3) knowing how to care for the lathe, 4) being able to make simple workpieces. Indicators of the success of this activity are participants can turn a simple workpiece, know how to maintain a lathe and increase knowledge about turning. Trainees sincerely hope that the turning training program can continue in the future.
\end{abstract}

Keywords: coaching, turning, independent

\begin{abstract}
Abstrak
Pengabdian kepada masyarakat ini merupakan wujud dari tri dharma perguruan tinggi seorang dosen supaya bisa memberikan manfaat bagi masyarakat. tujuan dari kegiatan ini adalah untuk memberikan bekal pengetahuan kepada pemuda karang taruna di pedukuhan Bromonilan Purwomartani Kalasan Sleman dalam hal: 1) memahami teori pahat bubut, 2) mengetahui cara pengoperasian mesin bubut, 3)mengetahui cara perawatan mesin bubut, 4) mampu membuat benda kerja sederhana. Kegiatan pengabdian ini dilakukan dengan memberikan kerampilan-ketrampilan dasar teori dan praktek membubut kepada para pemuda karang taruna, khususnya mereka yang putus sekolah, agar memiliki bekal dan pengetahuan praktis tentang membubut mereka dapat mandiri berwiraswasta, menciptakan lapangan pekerjaan sendiri serta menghidupi dirinya sendiri. Diharapkan secara umum dapat menggurangi pengangguran yang selanjutnya akan dapat menggurangi tingkat kemiskinan. Pelatihan dilaksanakan pada hari Senin-Selasa, 16-17 April 2018 di Laboratorium Teknik Industri Universitas Widya Mataram. Pelatihan diikuti oleh pemuda karang taruna padukuhan Bromonilan dan mahasiswa Teknik Industri UWM sebanyak 15 peserta. Kesimpulan dari kegiatan ini adalah: 1) pengetahuan peserta tentang membubut bertambah, 2) peserta mengetahui cara pengoperasian mesin bubut, 3) peserta mengetahui cara perawatan mesin bubut, 4) peserta bisa membuat benda kerja sederhana. Indikator keberhasilan kegiatan ini adalah peserta dapat membubut benda kerja sederhana, mengetahui cara perawatan mesin bubut dan bertambah pengetahuan mengenai pembubutan. Peserta pelatihan sangat berharap program pelatihan membubut bisa berlanjut di masa-masa mendatang.
\end{abstract}

Kata Kunci: Pelatihan, membubut, mandiri 


\section{PENDAHULUAN}

Dimasa sekarang mencari dan mendapatkan pekerjaan bukanlah hal yang mudah, terlebih bagi orang yang tidak mengenyam pendidikan atau tidak mempunyai keahlian. Untuk mendapatkan pekerjaan selain harus memiliki ijasah, orang harus memiliki ketrampilan yang memadai, dan untuk itu perlu biaya yang tinggi. Oleh karenanya seseorang harus memiliki keahlian dan ketrampilan untuk mendapatkan pekerjaan.

Seiring dengan perkembangan ilmu pengetahuan dan teknologi telah berhasil menciptakan teknologi pembubutan. Proses pembubutan adalah proses pemesinan untuk membuat bentuk dan ukuran benda kerja. Teknik kerja pembubutan ini adalah dengan cara menyayat benda kerja yang berputar menggunakan alat potong yaitu pahat yang terpasang pada mesin bubut. Benda kerja untuk proses bubut merupakan bahan setengah jadi hasil dari proses pengecoran dan pembentukan. Sedangkan Jenis-jenis produk yang berbentuk silinder banyakditemui pada komponen- komponen mesin dari ukuran kecil sampai ukuran besar. misalnya contoh komponen yang biasa dibubut adalah mulai baut ukuran kecil sampai besar, berbagai jenis poros, piston dan silinder, selongsong senjata, poros turbin dan sebagainya. Proses pembuatan produk-produk tersebut dilakukan dengan proses pemotongan pada mesin bubut, dimana proses berlangsung dengan cara memotong sebagian benda kerja yang berputar pada mesin sementara pisau potongnya diam. Menurut Widarto (2008) menyatakan bahwa bentuk dasar dalam proses bubut dapat didefinisikan sebagai proses pemesinan permukaan luar benda silindris atau bubut rata dengan benda kerja yang berputar, satu pahat bermata potong tunggal (with a singlepoint cutting tool), gerakan pahat sejajar terhadap sumbu benda kerja pada jarak tertentu sehingga akan membuang permukaan luar benda kerja.

Untuk lebih mengetahui dan memahami proses pembubutan perlu dilakukan praktik. Purnomo, dkk (2011) menyatakan bahwa praktik merupakan perwujudan dari teori dalam bentuk nyata yang didasari oleh teori tertentu. Dengan adanya teori pembubutan yang diberikan dilanjutkan dengan praktik langsung akan menambah pengetahuan. Pembubutan mudah dilakukan oleh siapapun seperti masyarakat ekonomi lemah yang mungkin dapat dipergunakan untuk berwiraswasta. Akan tetapi masyarakat umum masih jarang mendapatkan pengetahuan tentang membubut baik dari pendidikan formal maupun non formal. Khususnya bagi para pemuda yang putus sekolah namun mereka mempunyai kemauan yang keras untuk maju dan mau bekerja keras tetapi mereka tidak memilki ketrampilan.

Sasaran khusus kegiatan ini adalah pemuda karang taruna padukuhan Bromonilan Purwomartani Kalasan Sleman, dan sebagai khalayak tambahan adalah mahasiswa jurusan Teknik Industri Universitas Widya Mataram. Alasan dipilihnya pemuda karang taruna pedukuhan Bromonilan Purwomartani Kalasan Sleman karena adanya permintaan dari pemuda karang taruna daerah tersebut agar diberikan pelatihan membubut guna meningkatkan pengetahuan dan 
kemampuan mereka dalam membubut, sehingga diharapkan nantinya bisa membuka peluang kerja sendiri dan bisa meningkatkan taraf hidup.

Pelatihan membubut pernah dilakukan oleh beberapa instansi. Salah satunya adalah Sukardi, dkk yang berasal dari Jurusan Pendidikan Teknik Mesin UNY pada tahun 2016 dengan judul "Pelatihan Tool Grinding Pahat Bubut Tipe Oblique Untuk Meningkatkan Kompetensi Mengajar Guru SMK dan Kualitas Hasil Praktik Pemesinan Bubut di SMK DIY". Kegiatan pelatihan yang dilakukan adalah dengan memberikan teori, praktik mengasah pahat, dan praktik membubut.

Dari latar belakang masalah di atas pengabdian masyarakat ini merumuskan masalah sebagai berikut: 1) Bagaimanakah cara meningkatkan pengetahuan pembubutan para pemuda karang taruna padukuhan Bromonilan Purwomartani Kalasan Sleman dalam hal membubut? 2) Bagaimanakah memampukan pemuda karang taruna pedukuhan

Bromonilan Purwormartani Kalasan Sleman agar dapat membubut dengan baik? 3) Bagaimanakah cara untuk meningkatkan pengetahuan perawatan mesin bubut para pemuda karang taruna pedukuhan Bromonilan Purwomartani kalasan Sleman? 4) Bagaimanakah cara memampukan para pemuda karang taruna pedukuhan Bromonilan Purwomartani Kalasan Sleman supaya dapat membuat benda kerja sederhana dengan pembubutan?.

\section{Tujuan Kegiatan}

Tujuan kegiatan ini adalah untuk memberikan pengajaran teori pengetahuan, praktek membubut dan cara perawatan mesin bubut.

\section{METODE}

Metode yang dilakukan dalam kegiatan pengabdian kepada masyarakat ini adalah: ceramah, praktek, pendampingan dan evaluasi. Metode ceramah dilakukan dengan memberikan pengetahuan teori dasardasar membubut serta berdiskusi sehingga peserta mempunyai gambaran awal tentang mesin bubut. Metode praktek yaitu dengan mempraktekkan secara langsung apa yang telah didapat melalui teori dengan mencoba langsung di lapangan dengan menggunakan mesin bubut. Metode selanjutya adalah pendampingan. Dalam melaksanakan praktek secara langsung peserta didampingi oleh pendamping yang berkompeten dalam hal pembubutan. Tujuan pendampingan ini tentunya peserta mengalami kesulitan bisa langsung menanyakan ke pendamping. Dan jika ada kesulitan bisa langsung diatasi. Metode selanjutnya adalah evaluasi. Evaluasi bertujuan untuk mengetahui apakah teori yang telah telah didapat oleh peserta bisa dipraktekkan secara benar atau tidak. Selain itu juga untuk mencari solusi dari permasalahan yang dihadapi selama kegiatan pengabdian kepada masyarakat. Sebelum melaksanakan kegiatan, disusun rencana kerja sebagai berikut:

a. Persiapan materi ceramah, teori dan praktek, yang meliputi dasar-dasar teknik membubut

b. Ceramah tentang teori dan Praktek membubut

c. Bersama dengan pemuda karang taruna menentukan jadwal 
pelaksanaan yang meliputi pembagian hari pelaksanaan.

d. Setelah selesai pelaksanaan dilakukan evaluasi untuk mengetahui perlu tindak lanjut atau tidak agar sasaran dari pengabdian kepada masyarakat tercapai.

Adapun langkah-langkah dalam kegiatan pengabidan kepada masyarakat ini adalah :

1. Pemberian materi atau teori dasar mengenai jenis mesin bubut, bagian-bagian dari mesin bubut, jenis-jenis model pahat bubut, cara mengoperasikan mesin bubut, cara perawatan mesin bubut, prosedur pembuatan benda kerja dengan menggunakan mesin bubut.

2. Praktek membubut benda kerja sederhana

Selain itu dilakukan pendampingan secara langsung selama pelatihan berlangsung, sehingga jika ada peserta yang belum paham bisa langsung bertanya dan ditangani.

\section{HASIL DAN PEMBAHASAN}

Hasil kegiatan pengabdian kepada masyarakat telah dilaksanakan pada tanggal 16-17 April 2018 bertempat di Laboratorium Teknik Industri Universitas Widya Mataram. Kegiatan ini diikuti oleh 15 peserta dari pemuda karang taruna pedukuhan Bromonilan Purwomartani Kalasan Sleman dan mahasiswa jurusan Teknik Industri UWM. Kegiatan pengabdian kepada masyarakat yang berlangsung selama dua hari ini diikuti dengan antusias oleh para peserta yang mengikuti kegiatan ini dari awal hingga akhir. Dalam kegiatan pengabdian ini dibantu dosen Teknik Industri UWM yang expert dibidang pembubutan yaitu Ir. Suhartono, MT.
Pada sesi penyampaian materi, para peserta mendengarkan ceramah dengan cermat dan diperkenankan bertanya jika ada sesuatu hal yang tidak atau belum mereka pahami. Untuk meningkatkan pengetahuan mengenai mesin bubut, maka dalam pelatihan ini disampaikan materi mengenai bagian atau komponen mesin bubut, macam-macam jenis pahat bubut, cara pengoperasian dan perawatan mesin bubut oleh Iva Mindhayani, ST., MT. Peserta diberikan petunjuk teknis tentang cara menggunakan dan mengoperasikan mesin bubut yang baik dan benar serta aman. Peserta juga diberikan petunjuk tentang keselamatan kerja. Materi disampaikan oleh pemateri selama kurang lebih satu jam. Dalam pemaparan tersebut disampaikan klasifikasi jenis pahat bubut dan jenis pembubutan. Para peserta mengikuti dengan semangat dan antusias serta bertanya beberapa hal terkait dengan materi yang disampaikan.

Materi selanjutnya adalah mengenai proses perencanaan pembubutan yaitu dengan menetapkan angka putaran mesin dan menghitung kecepatan potong. Karena dalam proses pembubutan kecepatan ditentukan oleh besaran putaran benda kerja dan diameter yang disayat, hubungannya adalah: dalam prakteknya nilai kecepatan potong ditetapkan, dan putaran mesin dicari.

Selain itu peserta juga diberikan materi mengenai pemilihan jenis pahat bubut. Pahat bubut harus disesuaikan dengan bahan yang dikerjakan dan proses pembubutan yang dilakukan. Dalam proses pembubutan, terdapat berbagai macam proses dan bahan benda kerja yang dibubut, dimana 
setiap jenis proses dan bahan yang dikerjakan memerlukan jenis pahat yang berbeda-beda serta spesifik. Pemilihan jenis pahat yang tepat akan menghasilkan kualitas hasil pembubutan yang optimal dan presisi sesuai standar yang ditentukan. Kepresisian dan kesesuaian dengan standar merupakan hal penting yang harus dipenuhi dalam proses pemesinan. Penyampaian materi peserta pelatihan dapat dilihat pada Gambar 1.

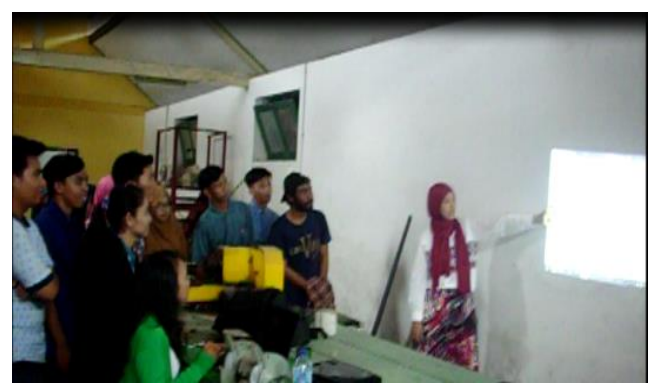

Gambar 1. Penyampaian Materi Bubut

Pada saat penyampaian materi pengabdi melakukan tanya jawab dengan peserta. Tanya jawab bertujuan untuk mengetahui sampai sejauh mana peserta bias menerima materi yang disampaikan oleh pengabdi.

Selain penyampaian materi dengan ceramah, dalam kegiatan pelatihan membubut ini peserta juga diajak melakukan praktek secara langsung. Setelah peserta mengetahui teorinya, maka peserta diminta langsung mempraktekkannya sehingga mereka benar-benar bisa dan paham tentang seluk beluk pembubutan. Praktek pembubutan di bimbing oleh Ir. Suhartono, MT. Sebelumnya peserta diperkenalkan secara langsung dengan mesin bubut seperti terlihat pada Gambar 2.

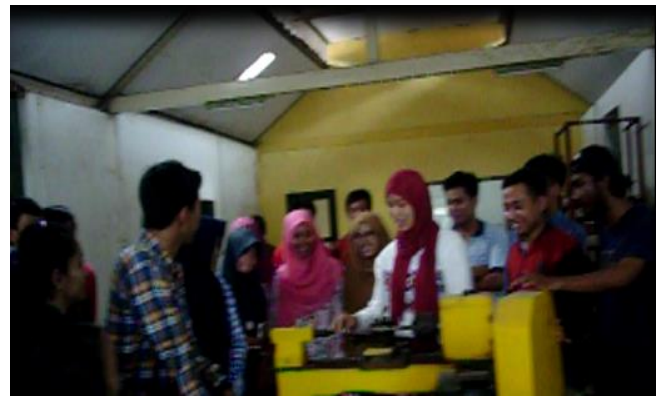

Gambar 2. Pengenalan dan Praktek Membubut

Pada saat praktek membubut beberapa peserta masih merasa bingung dan canggung karena belum pernah melakukan pembubutan sebelumnya. Akan tetapi adanya pendampingan secara langsung membuat peserta tenang. Pada kegiatan ini peserta juga diberikan pengetahuan tentang cara perawatan mesin bubut. Tujuannya adalah supaya peserta bisa merawat mesin bubut secara benar.

Berdasarkan respon para pemuda karang taruna di pedukuhan Bromonilan, Purwomartani, Yogyakarta setelah pelatihan membubut, dapat diketahui bahwa pelatihan tersebut sesuai dengan yang di butuhkan para pemuda karang taruna di padukuhan Bromonilan, Purwomartani.

Dalam pelaksanaan pelatihan membubut dilakukan evaluasi. Hasil evaluasi kegiatan terdapat kekurangan dimana mesin bubut yang ada di Laboratorium Teknik Industri UWM hanya ada satu, sedangkan peserta pelatihan diikuti sebanyak 15 orang sehingga praktek secara langsung kurang maksimal. Peserta tidak bisa pratek satu per satu dikarenakan terbatasnya peralatan dan waktu pelaksanaan yang hanya 2 hari juga masih dirasa kurang, sehingga pelaksanaan kegiatan ini masih belum efektif dan optimal. Namun demikian peserta bisa merasakan manfaat 
setelah mengikuti pelatihan ini. Peserta yang awalnya belum mengetahui tentang mesin bubut serta cara kerja mesin bubut menjadi bertambah pengetahuannya.

Dengan adanya pelatihan ini, pemuda karang taruna di Padukuhan Bromonilan, Purwomartani Yogyakarta mendapatkan pengetahuan mengenai teknik membubut, diharapkan bisa berguna dan menjadi bekal para pemuda karang taruna ke depannya. Meskipun pelatihan yang dilakukan belum maksimal. Selain itu dengan adanya pelatihan membubut ini bisa menumbuhkan jiwa mandiri berwiraswasta. Peserta sangat berharap kegiatan pelatihan membubut akan berlanjut di masa-masa mendatang dan diadakan secara kontinyu sehingga bekal keahlian yang diberikan bisa lebih bermanfaat.

\section{PENUTUP}

\section{Kesimpulan}

Berdasarkan hasil dari kegiatan pengabdian kepada masyarakat ini, dapat diambil kesimpulan sebagai berikut:

1. Pemuda karang taruna padukuhan Bromonilan telah menerima pelatihan dan pengajaran teori pembubutan. Pelatihan dan pengajaran tersebut menambah pengetahuan tentang teori pembubutan.

2. Pemuda karang taruna padukuhan Bromonilan telah menerima pelatihan praktek pembubutan. Pelatihan dan pengajaran tersebut menambah ketrampilan pembubutan.

3. Pemuda karang taruna pedukuhan Bromonilan telah menerima pelatihan dan pengajaran teori dan praktek perawatan mesin bubut.
Pelatihan dan pengajaran tersebut menambah pengetahuan dan ketrampilan tentang perawatan mesin bubut.

4. Pemuda karang taruna di padukuhan Bromomilan dapat membuat benda kerja sederhana.

\section{Saran}

Berdasarkan hasil kegiatan pengabdian kepada masyarakat penulis memiliki beberapa saran antara lain; perlunya penambahan mesin bubut untuk kegiatan pelatihan. Mesin bubut hanya ada satu sehingga kegiatan pelatihan kurang maksimal dengan jumlah peserta sebanyak 15 orang. Selain itu, masukan dari peserta tentang kegiatan ini, peserta berharap adanya kelanjutan pelatihan membubut di masa-masa mendatang.

\section{DAFTAR PUSTAKA}

Purnomo, E., Sukardi., Paryanto., Ridwansyah, E., Wahyudi., Wijaya, D. 2011. "Pelatihan Teknologi Pengujian Geometrik Mesin Untuk Meningkatkan Kompetensi Pembelajaran Praktik Kerja Mesin Bagi Guru SMK Se-Wilayah DIY". Laporan PPM. UNY. Yogyakarta. 
Sukardi, T., Purnomo, E., Surono., Pamungkas, Y.A., Saputro, A.E., Bardan, M. 2016. "Pelatihan Tool Grinding Pahat Bubut Tipe Oblique Untuk Meningkatkan Kompetensi Mengajar Guru SMK dan Kualitas Hasil Praktik Pemesinan Bubut di SMK DIY”. Laporan PPM. UNY. Yogyakarta.

Widarto. (2008). "Teknik Pemesinan untuk SMK". Jakarta. Direktorat Pembinaan Sekolah Menengah Kejuruan-Departemen Pendidikan Nasional. 
